\title{
RESIDENTIAL DIFFERENTIATION AT TWO GEOGRAPHIC SCALES - THE METROPOLITAN AREA AND THE CITY: THE CASE OF TEL AVIV
}

\author{
Itzhak OMER \\ Department of Geography and Human Environment, Tel Aviv University, Israel
}

\begin{abstract}
The research of residential differentiation in cities is concentrated on one geographic scale such as metropolitan areas, cities, or counties. As a result, we have relatively little information regarding the extent of residential differentiation and its spatial pattern at different geographic scales. This paper examines the residential differentiation within the socio-spatial structure of the Tel Aviv metropolitan area as it was in 1995. The analysis is conducted at two geographic scales. The first analyzes the entire metropolitan area as one spatial entity; the second examines the 22 cities located within that area. We applied the method of classical factorial social ecology to investigate residential differentiation along the social dimensions of ethnicity, socio-economic status and family status (stage in the family life cycle) in their spatial expression at the metropolitan and city geographic scales. The findings indicated that residential differentiation in the metropolitan area and in cities tends to be dominated by the ethnic dimension, which is most closely associated with the socio-economic dimension. The relative independence of family status enables the formation of socially diverse residential areas which are often organized in nearly a sectoral-concentric pattern. In general, residential differentiation was more significant at the geographic scale of cities.
\end{abstract}

Key Words: factorial social ecology, residential differentiation, geographic scale, ethnicity, Tel Aviv metropolitan area.

\section{Introduction}

The concept 'scale' is various defined in research of city. As Batty (2005) points out, we use scale to describe two things: the level of resolution at which we observe the city, such as streets and neighborhoods, and the level of functional differentiation that takes place at diverse locations or city sizes (Batty 2005, p. 34-36). These two meanings of scale are central to the research of urban residential differentiation or segregation. Yet, the literature often does not clearly distinguish between the two meanings, a situation that has led to their inconsistent application. Here we use the term 'level of resolution' to refer to the size of the spatial unit for which data are collected (e.g., streets, blocks, quarters) and the term 'geographic scale' to refer to the various functional levels of a geographic area (i.e., the location in which residential segregation is examined, such as the nation-state, county, metropolitan area and city $)^{1)}$.

The research of residential differentiation in cities varies by the level of resolution, the analysis of socio-demographic variables (e.g. socio-economic status and ethnicity) and the dimensions of segregation (e.g., evenness, exposure and clustering) examined. Common to most of this research is the concentration on one geographic scale, whether metropolitan areas, cities, or counties. We consequently have relatively little information regarding the extent of residential differentiation and its spatial expression at different geographic scales (Reardon et al., 2009).

1) Our use of the term 'geographical scale' corresponds to Reardon et al.'s (2008) definition: "the dimensions of identifiable social or physical features of a landscape". 
The geographic scale at which residential differentiation appears dominant is a crucial variable for the description and understanding of residential segregation and inter-group exposure. In recognition of its importance, several authors have recently referred to the intensity of segregation - especially racial segregation - at different scales: tracts, cities, and suburbs in U.S. metropolitan areas (Farrell, 2008; Fischer, 2004; Reardon et al., 2008; 2009). Analysis of residential segregation at different geographic scales is also necessary to improve our understanding of the development of metropolitan areas impacts on the social segregation within cities and suburbs as well as the spatial expression of that segregation. Such an analysis would enable the investigation of questions such as: Are the social dimensions of residential differentiation and their spatial expression similar on the metropolitan and the city scale? Does the classic three-factor model of residential differentiation (family status, socio-economic status and ethnicity) and its spatial expression as elaborated in 'factorial social ecology' (also known as 'social ecology' or 'urban ecology') studies apply equally to the metropolitan and the city scale (Fischer, 2004)?

The aim of the current study is to investigate the socio-spatial structure of the Tel Aviv metropolitan area in its 1995 structure at two geographic scales. The first analyzes the Tel Aviv metropolitan area as one spatial entity; the second examines the 22 cities located within that area. The Tel Aviv metropolitan area is currently at an advanced stage of development when compared to other metropolitan areas in Israel (Shachar, 1997); its residents in 1995 represent $57 \%$ of Israel's total urban population. Based on the factorial social ecology methodology as applied to cities, we examine the relative involvement and importance of socio-economic status, ethnicity and family status as sources for the formation of residential patterns of diverse social areas on each of the two scales.

The examination of socio-spatial structure on these two scales will enable formation of responses to two questions. First, how is Israel's social structure reflected in residential patterns on both these levels? An especially salient factor requiring in-depth study among the Jewish population is ethnicity. In Israel, this factor is related to the country of origin, most commonly between "Mizrahim" (of Near Eastern and African origin) and "Ashkenazim" (of European and American origin). Within such a context, the relationship of ethnicity to socioeconomic status is especially germane. For instance, how does the residential environment reflect trends in intensifying ethnicity and multiculturalism on the one hand and increasing inequality in income distribution on the other (Cohen, 1998; Yonah and Shenhav, 2005)? Second, an understanding of the socio-spatial system on multiple scales is necessary for our ability to respond to the question of whether metropolitan areas and the cities within them can be considered distinct socio-spatial entities. In our case, we ask how does consolidation of a socio-spatial structure as part of the development of metropolitan Tel Aviv affect the residential patterns of distinctive social areas within its cities? That is, do the metropolitan area's cities represent part of socially distinct areas within the emerging metropolitan area or do they also represent autonomous socio-spatial entities having their own unique socio-spatial structure?

The paper is organized as follows. The first part presents the methodological framework, including a brief review of the principles of factorial social ecology as applied in Western cities, a delineation of the research questions as well as a description of the variables, the data and the statistical analysis. The second part will focus on the socio-spatial organization of metropolitan Tel Aviv. In the third part, we discuss the socio-spatial character of the cities within the metropolitan area. In the fourth part we present the research findings and our conclusions. 


\section{Methodological framework}

One of the basic issues raised in research on social geography pertains to the major social dimensions of residential differentiation, the magnitude of segregation related to these dimensions in addition to their geographic manifestation. Based on the study of various Western cities during the modern era, considerable data has accumulated indicating the priority of three dimensions in the determination of urban residential distribution: socio-economic status, ethnicity and family status (stage in the family life cycle). A statistical analysis of the spatial organization of European and American cities by means of factorial ecology has produced two important findings (Berry and Kasarda, 1977; Davies, 1984; Davies and Murdie 1991; Wyly, 1999): (a) the major social dimensions are quite distinguishable and (b) among the three dimensions, socio-economic status is generally the main factor determining population distribution by residential area.

The priority of socio-economic status over ethnicity and the considerable lack of connection between the social dimensions reflect three variables that distinguish contemporary Western cities from cities found in traditional societies, where social areas are primarily ethnic in character. First, access and housing market conditions allow considerable spatial spread of residential housing when compared to the functional center of the city. Second, the separation between a person's achievement status from her ascription status is expressed in the interdependence between socio-economic status and ethnicity. Third, socio-economic status is a more powerful determinant of residential location than is ethnicity.

Social ecological studies have shown that European and American cities closely resemble one another in their spatial expression of social dimensions, with each social dimension exhibiting a consistent and distinctive spatial pattern (Cadwallader, 2001; Davies, 1984; Davies and Murdie 1991; Wyly, 1999). Figure 1 presents an ideal representation of these spatial patterns.

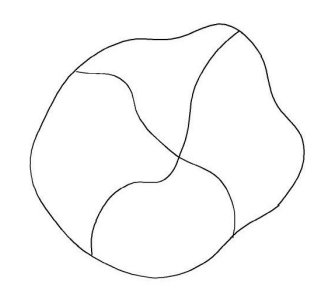

a

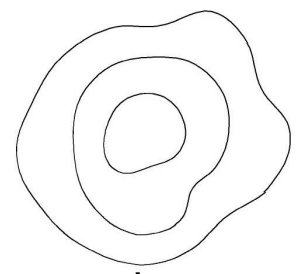

b

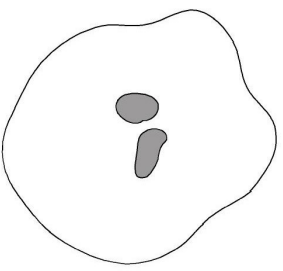

C

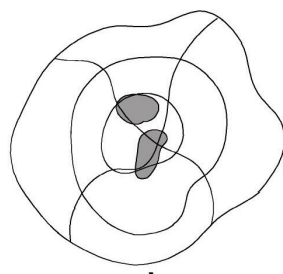

d

Fig. 1 - Idealized spatial patterns of the factorial ecology model: (a) socio-economic status - sector pattern; (b) family status - concentric pattern; (c) ethnicity - enclaves; (d) composite model (sector-concentric-enclave lattice). (after: Cadwallader, 2001).

The spatial distribution of the population along the socio-economic dimension can be identified in the sector pattern that emerged from the upper classes' tendency to select prestigious places of residence (Fig. 1a). The scope and location of the respective sectors thus express the city's socio-economic (or class) structure. In contrast, distribution of the population according to the family status creates a pattern of concentric areas, with each area representing a different stage in the family life (Fig. 1b). In the city center, we generally find small families with a very young or elderly head of household, meaning the absence of families 
in the early stages of the life cycle, that is, families having a large number of young children.

In contrast, the ethnic dimension creates a pattern of enclaves (Fig. 1c). In a society where ethnic minorities are minimal, the sector and concentric patterns merge to create a composite model comprised of sectors, concentric rings and enclaves, articulated in a wide variety of social areas within the city (Fig. 1d). Given its spontaneous emergence, the composite sectorconcentric pattern can be considered as complementing two social forces, with the first reflecting inter-group relationships and the second reflecting relationships to the city center.

It is worth noting that despite the transformations undergone by cities in the postmodern and global era (e.g., Castells 2002), expressed in the formation of unique as well as heterogeneous social areas in the city, the factorial ecological model has yet been found relevant for understanding the social structure of Western cities (Davies and Murdie 1991; Wyly, 1999). Notwithstanding the above, research on socio-spatial structure and the relative dominance of different dimensions has been undertaken on a single geographic scale, usually on the level of the metropolitan area.

However, in this research we examine the socio-spatial structure of the Tel Aviv metropolitan area as a whole as well as the cities within it while testing for the dominance of the social dimensions and emerging spatial patterns. To do so we apply the factorial ecology methods ('social area analysis' and 'principal component analysis'). The residential segregation is referred to through the dimension of evenness as indicated by the means of 'coefficients of variation' $(\mathrm{CV})^{2}$.

The social composition of the Tel Aviv metropolitan area, like that of Israeli society in general, is unique primarily due to its highly varied ethnic composition. As a result, the Jewish population is characterized by polarization based on country of origin (Mizrahim versus Ashkenazim), ethnicity-community (Jews versus Arabs), religiosity (the ultra-Orthodox versus the secular) and, to some degree, type of workers (foreign versus local). Here we focus on the ethnicity-community dimension among the Jewish population.

Research in the socio-spatial structure of Israel's metropolitan areas and cities, especially when applying the factorial ecology approach, has indicated that the ethnicity-community dimension, together with socio-economic status and family status, are dominant in the formation of social areas. This research includes the Haifa metropolitan area (Gradus 1976) and cities such as Ashqelon and Rehovot (Krakower, 1989), and Beer-Sheva (Gradus and Blustein-Libnon, 2001), but primarily the city of Tel Aviv and the Tel Aviv metropolitan area (Hasson and Choshen, 2003; Schnell 2009). Studies conducted in 1961 and 1972 on the socio -spatial structure of the Tel Aviv metropolitan area (Hershkovitz, 1984; Shachar et al., 1978) reported considerable association between the ethnicity-community, the demographic and the socio-economic dimensions, a phenomenon also found in some developing countries (Shachar et al., 1978). Nonetheless, as Hershkowitz (1984) has reported, during the 1960s (between the 1961 and the 1972 census), changes occurred that provide evidence for the weakening of this association: first, family status begins to act "independently"; second, a "weakening of the association between the ethnic-communal and the socioeconomic dimension" became evident (Hershkowitz, 1984, 53). The current investigation was conducted, among other things, to ascertain whether this trend was continuing.

2) The Coefficient of Variation (CV) is defined as the ratio of the standard deviation to the mean. We used $\mathrm{CV}$ instead of standard deviation in order to enable comparison of dimensions that have different means and units as well as different geographic scales. 


\section{Research objectives}

The purpose of the current research was to estimate the relative influence of socio-economic status, ethnicity and family status as determinants of the division of the Tel Aviv metropolitan area and its cities into social areas. In the course of the research we also attempted to explore whether a common socio-spatial pattern for Israeli cities could be discern. Specifically, the investigation aimed to provide answers to the following questions:

1. What is the level of congruence or separation between the social dimensions, especially ethnicity and socio-economic status, and what is the spectrum of social areas consequently created?

2. What is the relative dominance of each social dimension as a determinant of socio-spatial differentiation?

3. What spatial patterns do social areas emerging within a metropolitan area and its cities exhibit?

Definitions: Research scale, data and variables

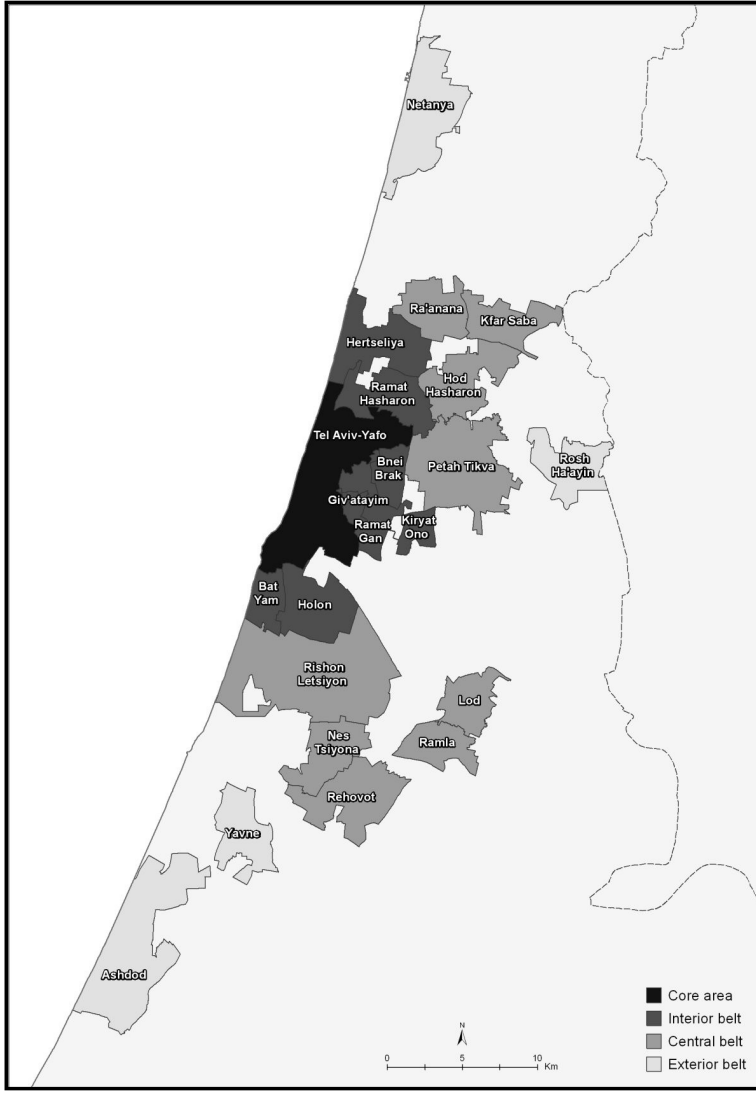

Fig. 2 - Spatial structure of the Tel Aviv metropolitan area and its cities.
The current research focuses on the Tel Aviv metropolitan area as defined in 1995 by the Israel Central Bureau of Statistics (ICBS) (see Fig. 2).

The research covers those urban settlements in the area having a population of over 20,000 in 1995 . This group includes 22 settlements that we will refer to as "cities in the Tel Aviv metropolitan area". The total population of the selected cities in 1995 was about 2.1 million out of a total population of 2.5 million residing within the Tel Aviv metropolitan area. The data, by urban statistical area, was obtained from the 1995 Census of Population and Housing, the most detailed of all CBSpublished surveys.

In factorial social-ecological studies generally, the variables representing the social dimensions are defined as follows: socio-economic status is represented by average (monthly) income and median education; family status (stage in the family life cycle) is represented by the percentage of children aged $0-14$ as well as family size; ethnicity-community is represented by the percentage of people of Asian (primarily NearEastern) and African origin among the Jewish population (i.e., the proportion of 
the population born in Asia-Africa or whose fathers were born in Asia-Africa among all Jewish residents in a statistical area) ${ }^{3)}$. People of Asian-African origin represent about $37 \%$ of the entire population covered in the research (about 2.1 million people). For the sake of simplicity, we will use the phrase "Mizrahi origin" when referring to this group and the term "Western origin" when referring to the rest of the population even though it may include Israeli-born children of fathers also born in Israel.

Because ethnicity-community is relevant solely to the Jewish population, and because our purpose was to examine the relationship of this variable with other variables, we focus here on the Jewish population only. A complementary and separate study was also conducted among the Arabic population in Ramle ${ }^{4}$, Lod and Tel-Aviv-Yafo, cities having a notably Arab presence. This second study included an investigation into the relative importance of ethnicnational identity (Arab versus Jew) in comparison to the other social dimensions: socioeconomic status, family status and ethnicity-religiousity (Christian versus Muslim) as determinants of the Arabic population's distribution among various residential areas.

\section{Socio-spatial structure in the Tel Aviv Metropolitan Area}

Our investigation as reported in this section was aimed at shedding light on the consolidation of social areas and on their residential spatial patterns as they appear in metropolitan Tel Aviv. This part of the study was based on an estimation of the level of association between social dimensions, their relative dominance and the organization of the subsequent spatial patterns.

The association between the social dimensions. Estimation of the association between the social dimensions was conducted by means of a correlation analysis, as applied in the 'social area analysis' approach. The relationship between the social dimensions was examined at the level of resolution of statistical areas (the most detailed spatial units for which census data are published by the ICBS). Included in the examination were all the statistical areas demarcated within the cities in metropolitan Tel Aviv (a total of 665 areas). Results of the model are presented in Table 1.

Table 1

Correlations between the social dimensions in metropolitan Tel Aviv.

\begin{tabular}{|l|c|c|c|c|c|c|}
\hline \multicolumn{1}{|c|}{$\begin{array}{c}\text { Social } \\
\text { Dimension }\end{array}$} & Variable & $\begin{array}{c}\% \text { of } \\
\text { Children }\end{array}$ & $\begin{array}{c}\text { Family } \\
\text { Size }\end{array}$ & $\begin{array}{c}\text { 'Mizrahi' } \\
\text { origin }\end{array}$ & Income & Education \\
\hline $\begin{array}{l}\text { Family status (life-cycle } \\
\text { stage) }\end{array}$ & $\%$ of Children & ----- & & & & \\
\hline & Family Size & 0.85 & ----- & & & \\
\hline Ethnicity & 'Mizrahi' origin & 0.16 & 0.25 & ----- & & \\
\hline \multirow{2}{*}{ Socio-economic status } & Income & -0.11 & 0.04 & -0.47 & ----- & \\
\cline { 2 - 8 } & Education & -0.09 & -0.15 & -0.45 & 0.53 & - ----- \\
\hline
\end{tabular}

All the correlation coefficients whose absolute values were greater than 0.1 were found to be significant at the level of 0.001 . The results indicated a clear and meaningful correlation

3) Two variables were used to construct this variable: the percentage of those born in Asia-Africa (of all those born abroad) and the percentage of the population in which the father was born in Asia-Africa (of all Israeli-born). The decision to combine the two variables into one variable was based on findings indicating that Mizrahi immigrants (the first generation) and their children (the second generation) evidence similar socio-economic characteristics (see for example Cohen 1998).

4) ICBS publications do not list "nationality" but do use religion as an indicator differentiating between the Jewish and non-Jewish population. The Arabic population was therefore considered here as part of the non-Jewish population. 
between ethnic origin and first, level of income and second, education stood at -0.47 and -0.45 , respectively. These correlations indicated a significant association between the presence of families of Mizrahi origin and the presence of families of low socio-economic status within the same statistical areas. In contrast, excluding a moderate association between large families and families of Mizrahi origin, we find the residential distribution of the family dimension to be quite independent of the effects of the other dimensions. These findings indicate the possibility of consolidating diversified social areas within metropolitan Tel Aviv, the only exception being strong (i.e., wealthy) residential areas having a large proportion of Mizrahi residents.

Social Areas and their Geographic Distribution. In order to clarify how associations existing between the social dimensions were reflected in the consolidation of social areas, the SPSS program (ver. 11) was used to perform a principal component analysis in two ways. In the first, the analysis was conducted to clarify the variance between the variables without orthogonal rotation. In the second, the analysis was conducted according to the varimax criterion, an attempt was made to associate the minimum number of variables to each factor by means of orthogonal rotation. Results from the two analyses appear in Table 2.

Factor analysis of the variables representing the social dimensions

Table 2 in metropolitan Tel Aviv.

\begin{tabular}{|c|c|c|c|c|c|c|}
\hline \multirow[t]{3}{*}{ Variables } & \multicolumn{3}{|c|}{$\begin{array}{l}\text { Discrimination Axis } \\
\text { (Unrotated) }\end{array}$} & \multicolumn{3}{|c|}{$\begin{array}{l}\text { Discrimination Axis } \\
\text { (Varimax) }\end{array}$} \\
\hline & \multicolumn{3}{|c|}{ Factors } & \multicolumn{3}{|c|}{ Factors } \\
\hline & 1 & II & III & I & II & III \\
\hline $\begin{array}{l}\% \text { children aged } 0-14 \\
\text { Average family size } \\
\text { Mizrahi origin } \\
\text { Income } \\
\text { Education (median years of study) }\end{array}$ & $\begin{array}{r}.677 \\
.707 \\
.701 \\
-.613 \\
-.643\end{array}$ & $\begin{array}{r}.673 \\
.655 \\
-.363 \\
.561 \\
.499\end{array}$ & $\begin{array}{r}-.111 \\
.- \\
.607 \\
-.199 \\
-.361\end{array}$ & - & $\begin{array}{l}- \\
- \\
- \\
.876\end{array}$ & $\begin{array}{r}- \\
.141 \\
.935 \\
-.272 \\
-.131\end{array}$ \\
\hline
\end{tabular}

The geographic mapping of the factors allows us to observe the degree to which and where the social areas identified by the analysis are concentrated. Figure 3 presents a spatial representation for each social dimension obtained by factor analysis (varimax method) for each factors. Due to the multiplicity of statistical areas, the factors were mapped according to the average values computed for the metropolitan area's cities.

The result of the first analysis (without orthogonal rotation) indicated the formation of social areas along two main factors (axes) that together explained about $76 \%$ of the variables' variance. The first factor (Factor I), which explained $45 \%$ of the variance, differentiated between weak socio-economic areas in which there was a high rate of families of Mizrahi origin and young families, and strong socio-economic areas in which there was a high rate of Ashkenazi families of older family status. A review of the spatial distribution of this factor (Factor I, Fig. 3) indicated that this factor distinguished between areas located primarily in the metropolitan core (Tel Aviv and cities in the interior belt, Fig. 2) containing an economically weak, Mizrahi and young population, and areas located primarily in the metropolitan periphery (cities in the central and exterior belts) in which an economically strong. Ashkenazi and relatively mature population resides. Thanks to the dominance of family status in this factor, its spatial distribution tends to conform to the concentric spatial pattern, in which the weight of families found in the early stage of the family life cycle increased as one moved from the metropolitan core to its periphery. 


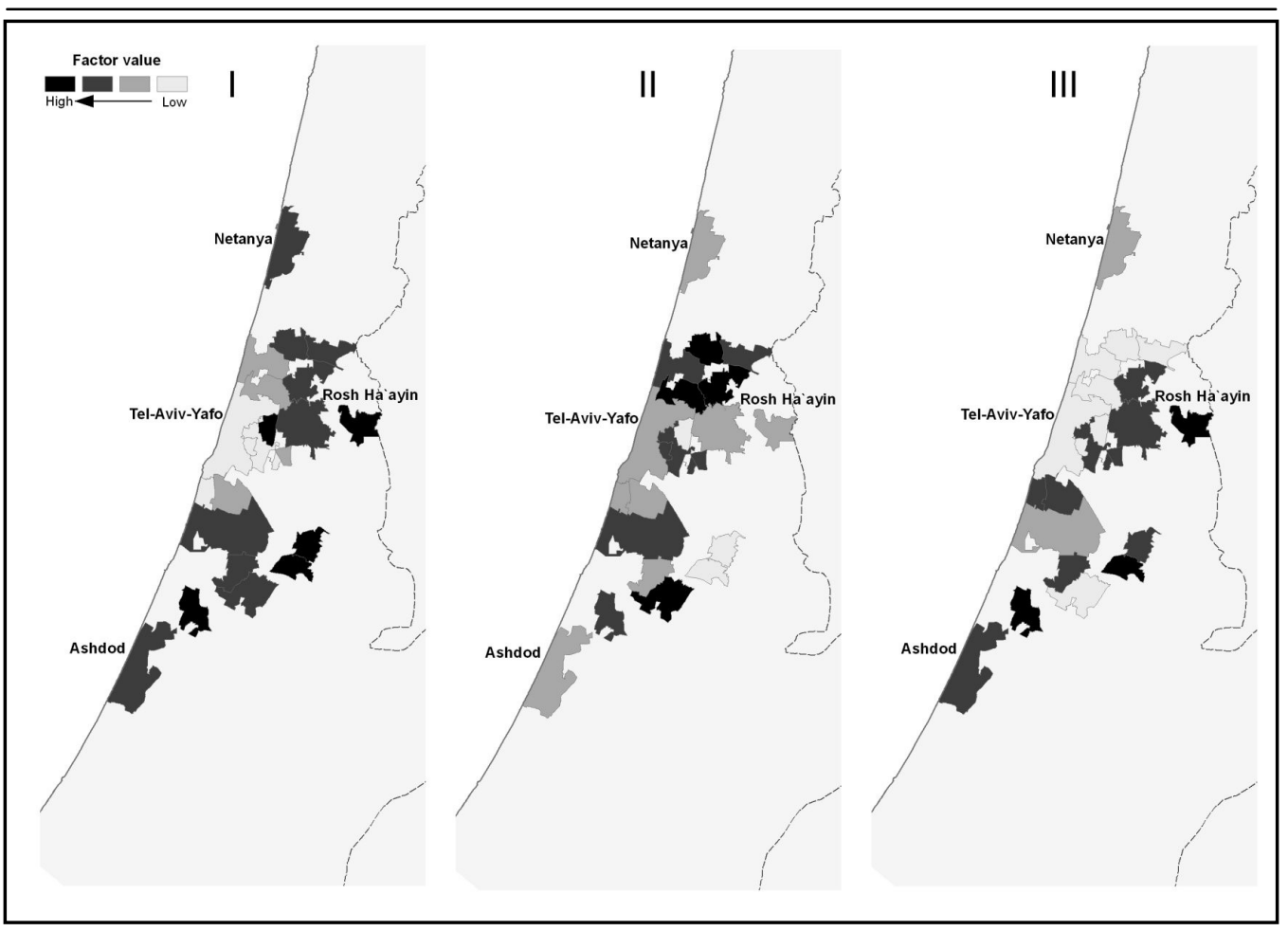

Fig. 3 - A spatial representation of the factor loadings representing the social dimensions in metropolitan Tel Aviv

(factor loadings are presented in terms of their averages in the cities in the Tel Aviv metropolitan area).

In contrast, the second factor (II), which explained about $31 \%$ of the variance, distinguished between strong socio-economic areas in which families in the early stages of the life cycle and of Ashkenazi origin were found from social areas in which families in later stages of the life cycle and of the Mizrahi origin were found. As we can conclude from its spatial distribution (Factor II, Fig. 3), this factor distinguished primarily between the metropolitan area's internal belts, which contained a young, Ashkenazi and wealthy population, and the metropolitan core as well as its periphery, in which we found an older, Mizrahi and economically weak population. With the exception of the concentration of high factor values in the northern sector of the internal and central belts, which stretch north of Tel Aviv (from Ramat HaSharon to Herzliya, Hod HaSharon, Kfar Saba and Raanana), an area that we treated as a relatively distinct sector, the spatial distribution of this factor made it difficult to identify specific sectors in other parts of the metropolitan area. Along the third factor, which explained only $11 \%$ of the variance, we identified social areas that could be distinguished primarily on the basis of ethnic and socioeconomic status, and only marginally according to family status. This implied that the spatial distribution of the population by family status did not follow the patterns set by socio-economic status or ethnicity.

These results were based on the association between socio-economic status and ethnicity, and the independence of family status from the effects of the other two dimensions. The association 
between the socio-economic dimension that was observed in each of the factors (see Table 2) also found clearer and visible expression in their spatial association (the loading on the city level was -0.55 with $p<0.01$ ).

A comparison of these findings with those obtained in other studies conducted in the same area during the 1960s (Hershkowitz, 1984) indicated that, on the one hand, family status has completed its separation from the other dimensions, a process begun in the early 1970s and, on the other hand, a considerable association continues to exist between socio-economic status and ethnicity, even if that association is less than what was observed in the 1970s.

\section{The socio-spatial structure of cities in the Tel Aviv metropolitan area}

A shift in perspective from the metropolitan area as a whole to the spatial structure of the area's cities was done to clarify the status of these cities as distinct socio-spatial entities. We first examined the degree of separation between the social dimensions and their relative dominance. We then examined the spatial patterns of social areas within selected cities. For the sake of simplicity and assuming that the variables constructing the social dimensions were sufficiently correlated, the variables percentage of children aged 0-14 and income level were chosen to represent the family and socio-economic dimensions, respectively.

Levels of association between the social dimensions. An examination of the correlations between the social dimensions by city indicated, as anticipated, that their associations were greater when conducted on the city scale than when conducted on the metropolitan scale. The examination indicated that when we lower the scale, the average correlation between socioeconomic status and ethnicity intensifies (from 0.47 on the metropolitan scale to 0.54 on the city scale), although we can also observe an increase in the correlation between family status and socio-economic status (from 0.11 to 0.34 ) as well as family status and ethnicity (from 0.16 to 0.23 ). The differences, however, were not great. Excluding the correlation between the socio-economic dimension and the family status dimension, which reflected a stage in the city's development, the composition of social areas in each city tended to resemble the composition of the social areas throughout the metropolitan area. Each of the metropolitan area's cities, excluding the city of Ashdod $^{5}$, exhibited a negative correlation between socio-economic status and ethnicity. Nonetheless, a highly varied range of values was obtained with no consistent correlations between family status and the other two dimensions (ethnicity and socio-economic status), as presented in Figure 4. As a result, the respective cities were distinguished by the type and variety of social areas within their boundaries as well as by the conditions supporting the formation of their spatial patterns.

As already noted, the consolidation of a combined pattern (sector-concentric) depended on a low correlation between socio-economic status and family status (the vertical dimension in Fig. 4). In the cities of Nes Ziona, Herzliya, Ramat Hasharon and Tel Aviv, for example, the low correlation between socio-economic status and family status provided more convenient conditions for the consolidation of a combined pattern in comparison to other cities, such Hod Hasharon, Givatayim and Lod, where those correlations are high. In contrast, the correlation between the family status and ethnicity (the horizontal axis in Fig. 4) was likely to weaken or, alternatively, strengthen this pattern.

5) The uniqueness of Ashdod is explained by the relatively high proportion of new immigrants who arrived from the former Soviet Union in 1990 and thereafter. This population is categorized as Western/ Ashkenazi The negative correlation between income level and Ashkenazi origin can thus be explained by this population relatively low income. 


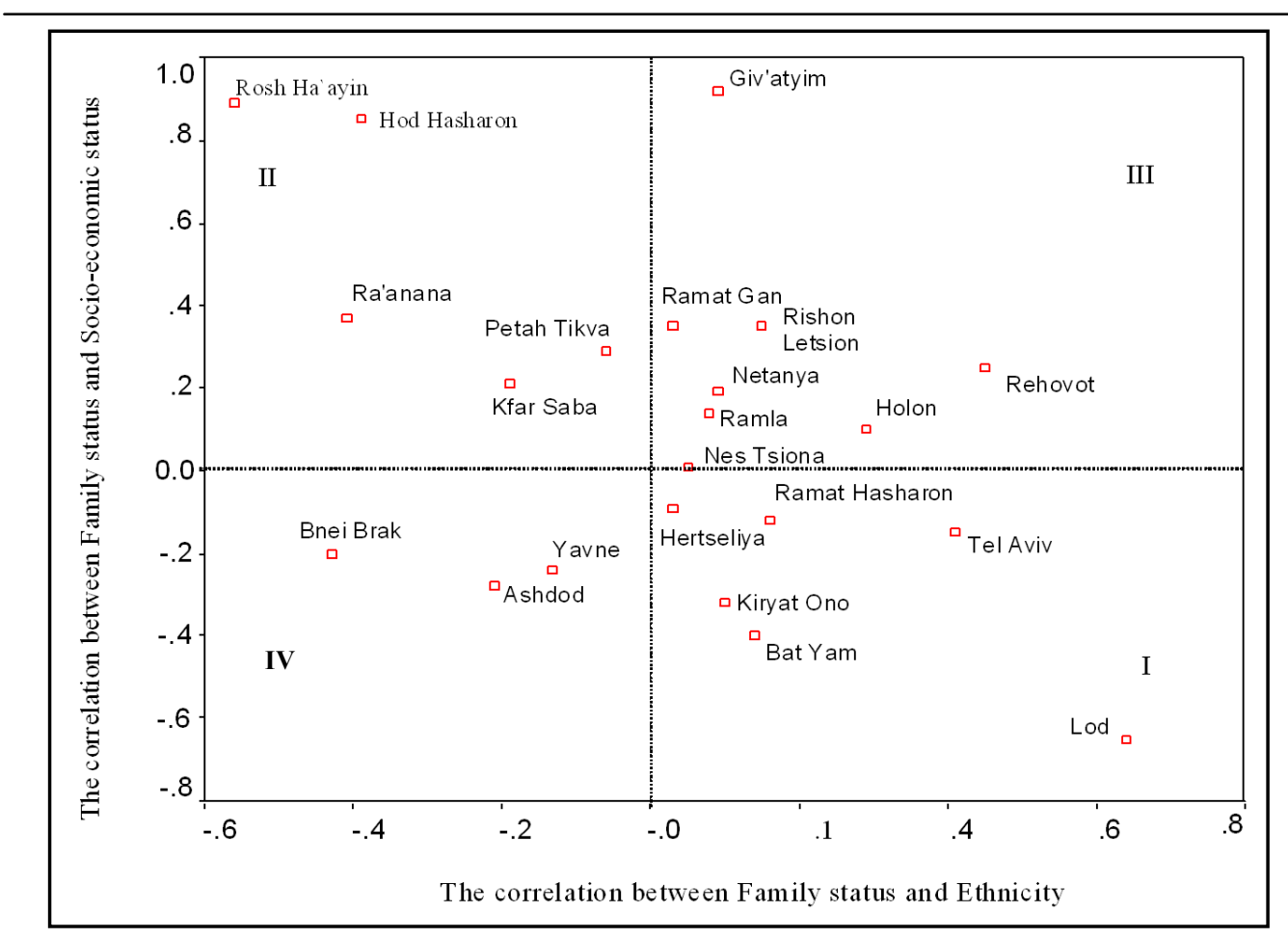

Fig. 4 - Correlation between the social dimensions in cities in metropolitan Tel Aviv

In order to categorize the cities according to the social areas within them, we found it convenient to distinguish between the four quadrants in Figure 4 that represent groups of cities according to the positive/negative values of their correlations. The correlation levels in the first group of cities (quadrant I) created conditions convenient for the existence of a relatively high frequency of only certain types of social areas, specifically, economically strong areas that were identified with older families of Ashkenazi origin; alternatively, they also supported the creation of economically weak social areas, identified with young families of Mizrahi origin. The frequencies of the areas depended on the strength of the correlations between the dimensions. The social areas that characterized the cities in the first group were not found at similar frequencies in other of the metropolitan area's cities, especially those located in the second group (quadrant II), which exhibited a greater frequency of social areas identified with young, economically strong families of Ashkenazi origin as well as social areas identified with families that are older, economically weaker and Mizrahi in origin. Such a mixture of social areas characterize cities such Rosh Ha'ayin and Hod Hasharon, which grew quickly as a result of the establishment of new neighborhoods occupied by a young and economically strong population during the 1980s and 1990s.

In contrast, the other two groups of cities (quadrants III, IV) exhibited no correlations between family status and socio-economic status with respect to ethnicity. Such a situation is potentially conducive to the creation of a wide range of social areas but, simultaneously, also presents difficulties in the consolidation of distinctive areas. In these two quadrants we can readily observe the absence of cities located far from the diagram's center; that is, there are no cities 
having social areas characterized by young families of Mizrahi origin who are economically strong (III) or areas in which the population is young, of Ashkenzi origin and economically weak (IV).

The relative dominance of social dimensions. In order to ascertain the relative dominance of the social dimensions in cities of Tel Aviv metropolitan area, the coefficient of variation (CV) was computed between the population distribution and each social dimension, by statistical area. The comparison of the $\mathrm{CV}$ values clearly revealed that the ethnic dimension is the most meaningful determinant of social segregation in the city. The CV for the socio-economic, the family and the ethnic dimensions on the city scale was $0.23,0.24$ and 0.34 , respectively, whereas the $\mathrm{CV}$ for these dimensions on the metropolitan scale (i.e., the variance between the average values for the 22 cities in the Tel Aviv metropolitan area) was $0.17,0.22$ and 0.23 , respectively. A comparison between the average variance for each of the cities and the average variance between the cities indicates that social segregation, especially polarization based on ethnicity, was greater within cities than in the metropolitan area as a whole. This finding implies that the city represents the geographic scale on which the most significant social segregation was found.

An analysis of the distribution of the cities according to their variance along the three axes representing the three social dimensions (Fig. 5) indicated that the relative dominance between the dimensions was not consistent. An attempt to identify the ordering principle behind their distributions led to the cities' categorization into four groups. The first group included cities such as Tel Aviv and Rosh Ha'ayin, where the coefficients of variation were higher than average for all the dimensions, especially ethnicity and socio-economic status. In the second group, which included cities such as Raanana and Kfar Saba, the relative dominance of ethnicity increased, with the variance significantly higher than average on the ethnic dimension yet lower with respect to the two other dimensions. The third group included cities such as Yavne and Rehovot, in which the ethnic as well as the socio-economic dimensions are relatively dominant. In contrast, as shown in Figure 5, in the fourth group of cities, which included Bat Yam, Givatayim, Holon and Nes Ziona, family status dominated.

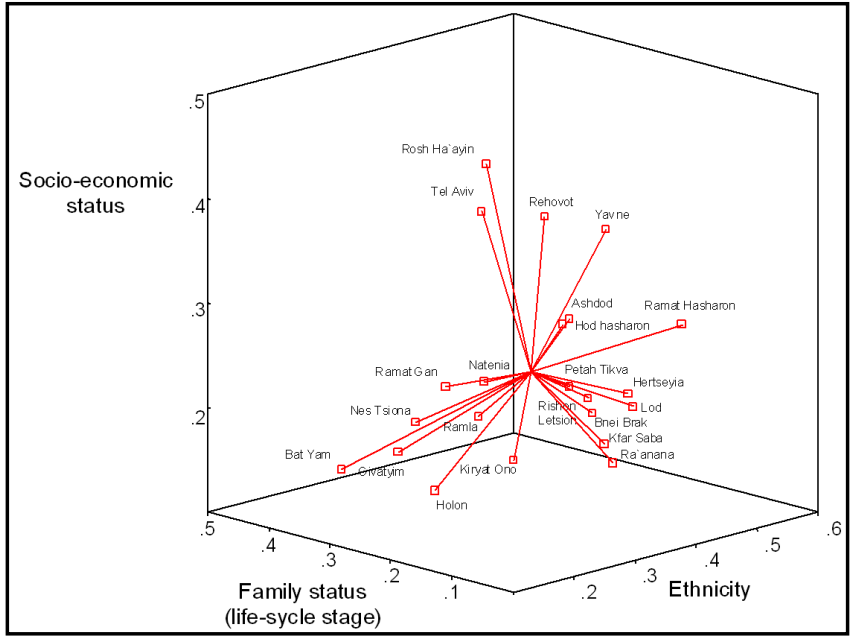

Fig. 5 - Coefficients of variation of social dimensions in cities in metropolitan Tel Aviv
The findings indicate clear association between the ethnic and the socio-economic dimensions in the cities located in the Tel Aviv metropolitan area. It is important to stress that thus association, as indicated here, made it impossible for a city to exhibit high socio-economic variance together with the low ethnic variance (the absence of such a possibility is quite striking, as seen in Fig. 5). Yet, the dependence between socioeconomic status and ethnicity was observed to be asymmetric. That is, socio-economic variance depended on the existence of ethnic variance, but not the opposite; we found no instance in 
which high socio-economic variance was accompanied by low ethnic variance. Although it was possible to find a small number of cases in which the opposite occurred, the overwhelming conclusion that emerged from this analysis is that social polarization can appear in every city in a metropolitan area characterized by the convergence of the ethnic dimension with the socioeconomic dimension.

The ethnic dimension has been found to be dominant in countries exhibiting the significant presence of an ethnic minority. Consider Montreal, where the French-speaking community represents a large minority population that is closely identified with low socio-economic status when compared with the English-speaking population, which is closely identified with high socio -economic status (e.g. Le Bourdais and Beaudry 1988).

In order to complete our analysis of the ethnic dimension, an additional and independent study was conducted among Arab residents in cities such as Ramle, Lod and Tel Aviv-Yafo, cities having a considerable Arab presence. An analysis of variance in the selected cities clearly indicated that the ethnic-national dimension was the major dimension determining segregation $(\mathrm{CV}=1.98)$. A comparison of the other dimensions studied here - the ethnicity- community $(\mathrm{CV}=$ $0.52)$, the socio-economic $(C V=0.35)$ and the family status $(C V=0.30)$ - were all less meaningful. When focusing solely on those residential areas in which Arab residents lived in significant numbers ${ }^{6}$, we found that the population was divided primarily according to ethnicreligious origin $(C V=1.14)$, a variable that divided the residents into Christians and Moslems, and to a lesser degree according to socio-economic status $(C V=0.41)$ and family status $(C V=0.43$. The implications of this finding are that the ethnic dimension represents the primary determinant of residential differentiation in mixed cities as well as among the Arab populations residing there.

Patterns of socio-spatial distribution in selected cities. In order to clarify as well as demonstrate the manner in which the relative dominance of the social dimensions and their correlations are expressed in spatial patterns within cities, we observed six cities that appeared to represent the range of patterns found in cities in the Tel Aviv metropolitan area. These cities were: Tel Aviv, Netanya, Ashdod, Bat Yam, Kfar Saba, and Ramle, cities that likewise represent different parts of the metropolitan area as well as city sizes. Figure 6 shows the spatial patterns observed in each according to the three social dimensions.

As already mentioned, Tel Aviv is notable in its socio-spatial polarization along each of these social dimensions as well as in the clear expression of integrated spatial patterns resulting from the very low correlation between the socio-economic and the family status dimension. We can also discern the variance of the family dimension is expressed in a concentric pattern according to the proportion of younger residents, which is low in the city center and high in its periphery. In addition, we see the variance in the socio-economic dimension as expressed in two distinct sectors that represent polarization between "North Tel Aviv" and "South Tel Aviv". It therefore appears that within each sector, the population is further divided by stage in the family life cycle. The association between ethnicity and family status implies that ethnicity is congruent with the sector-concentric spatial pattern. As we can see in the map of Tel Aviv (Fig. 6), it encompasses economically weak areas identified with a young population of Mizrahi origin or economically strong areas having few residents of Mizrahi origin.

6) Arab residential areas were defined as those statistical areas in which the non-Jewish population exceeded $40 \%$ (see note 2 ). 


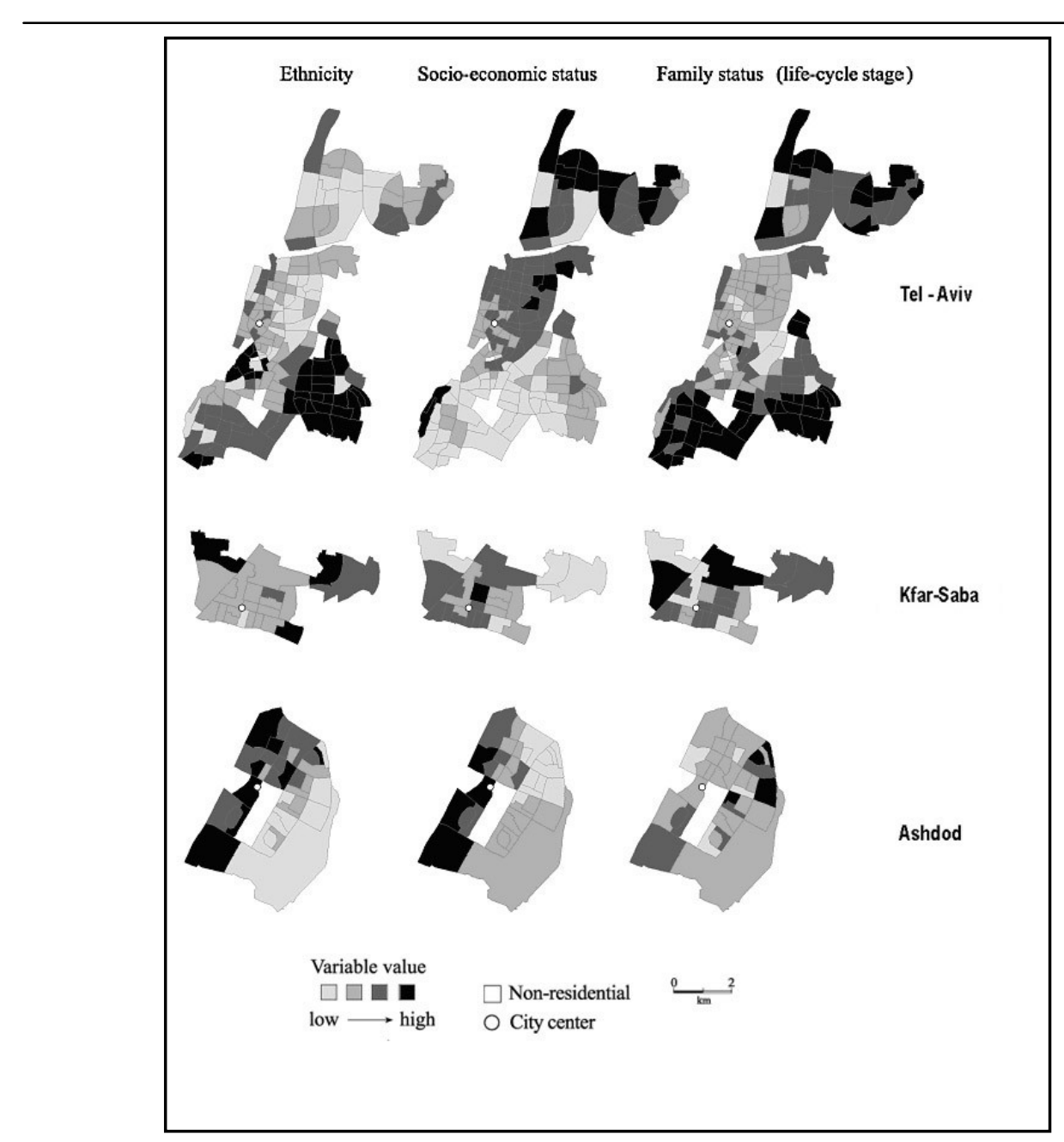

Fig. 6 - Spatial patterns of the social dimensions as observed in selected cities in the Tel Aviv metropolitan area

Kfar Saba is typical of those cities where ethnicity has priority over the two other dimensions but it also resembles those cities where economically strong residential areas are identified with young Ashkenazi families. Hence, we can readily observe that the spatial pattern expressing the ethnic dimension closely resembles the sector-concentric pattern ${ }^{7}$. Another case, Ashdod, is the only city in metropolitan Tel Aviv to exhibit a positive correlation between the ethnic and the socio-economic dimension. That is, an economically strong social area identified with a Mizrahi population and an economically weak social area having a higher rate

7) Even though the social-structural and ethnic polarization is expressed differently in Tel Aviv and Kfar Saba - north-south in Tel Aviv as opposed to core-periphery in the suburban cities - the source of this polarization can be associated with the settlement in the cities of new immigrants of primarily Mizrahi origin in the years prior to and immediately after establishment of the State. This phenomenon also found significant spatial expression between residential areas (Gonen 1984). 


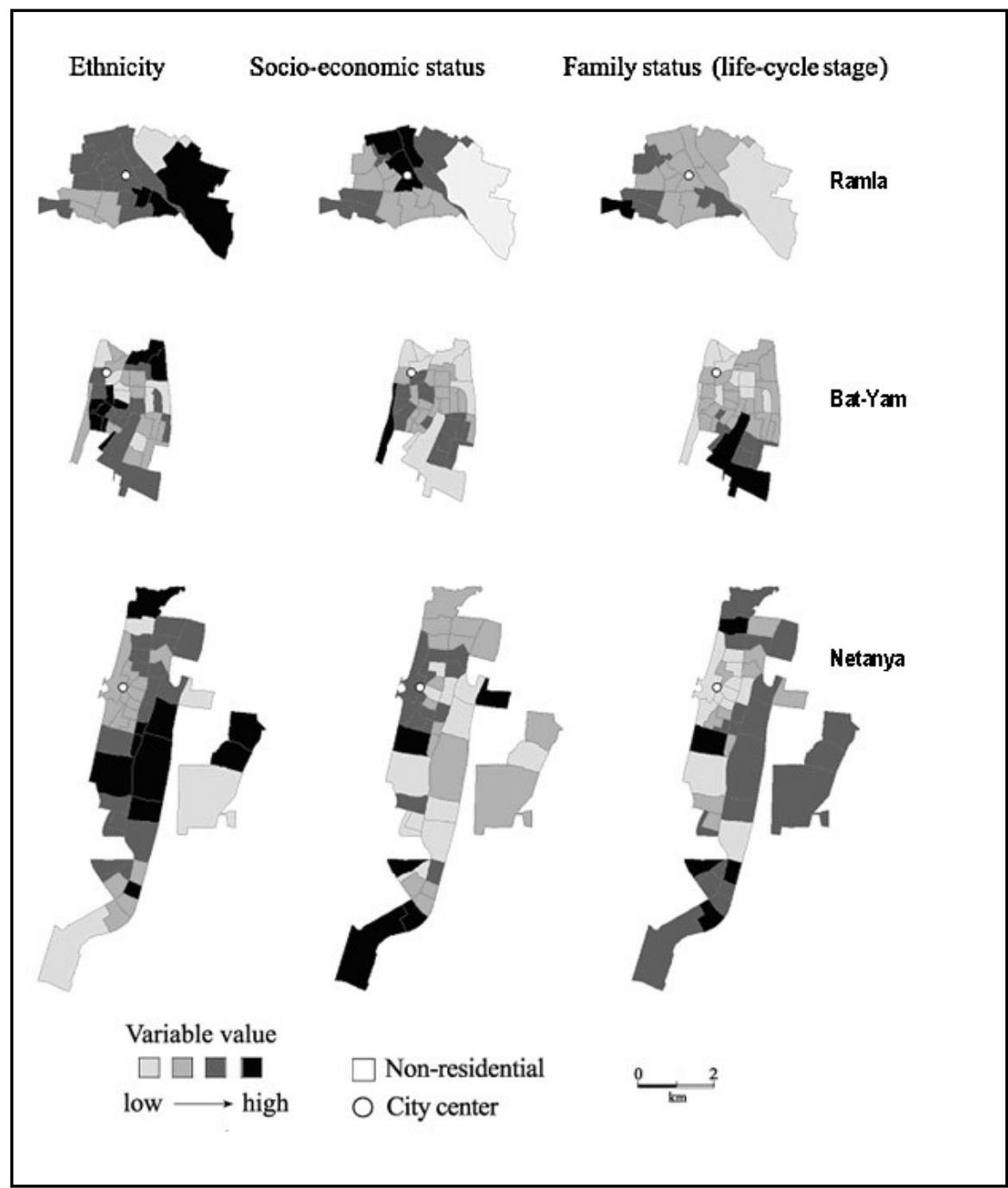

Fig.6 (continue) - Spatial patterns of the social dimensions as observed in selected cities in the Tel Aviv metropolitan area

of Ashkenazi residents (including a large proportion of new immigrants from the former Soviet Union). However, this unique phenomenon does not prevent the almost total spatial association between the ethnic dimension and the socio-economic dimension. In Ramle, we can clearly identify a tendency toward a sectoral-concentric spatial pattern as an expression of low correlations between the family dimension and the ethnicity and the socio-economic dimensions ( 0.09 and 0.19 , respectively).

The spatial patterns exhibited by the previously described cities represent the relative 
dominance holding between the social dimensions and their separation in cities found within the Tel Aviv metropolitan area. In addition to these, other relatively unique cities can be identified that can enrich the variety of socio-spatial patterns found in metropolitan Tel Aviv cities. Bat Yam, for example, represents a small group of cities in which family status dominates over the other two dimensions. The family status spatial pattern can thus be identified to a considerable extent according to its concentric form. Netanya's uniqueness is obvious in the weakness of the socio-economic dimension in comparison to the ethnic and the family dimensions. In addition, Netanya is included among the group of cities exhibiting little if any correlation between the family status and the socio-economic status with respect to the ethnic dimension, which may contain the potential for more numerous types of social areas. The combination of these two characteristics in Netanya expresses the difficulty involved in identifying some underlying order in the spatial patterns of its social areas.

The main findings from this investigation indicate that cities in the Tel Aviv metropolitan area are differentiated by the composition and variety of their social areas, primarily due to the different relationships holding between the family dimension and the other dimensions. These differences have not, however, prevented the consolidation of a composite spatial pattern in many of those cities. The findings thus imply that cities in the Tel Aviv metropolitan are generally autonomous socio-spatial entities having their own distinctive socio-spatial structure and evidencing significant social segregation.

\section{Findings and Conclusions}

The research reported here revealed three main findings.

(a) Ethnicity is a dominant source of social residential differentiation. The ethnic dimension was found to be a significant determinant for residential segregation, primarily at the city level. Moreover, in every city studied we also found that socio-economic segregation accompanied ethnic segregation. This finding is especially important in light of the fact that in the majority of western cities, socio-economic status represents the primary source of social segregation. The current findings can thus be explained by as well as support the position that despite the increasing economic inequality in Israeli society, this trend is, surprisingly, characterized by a rise in the importance of ethnicity (Cohen, 1998; Yonah and Shenhav, 2005). The ethnic dimension was also found to be dominant in mixed cities whereas the ethnic-national dimension is the major source for polarization among the Arab population, which is divided primarily according to the religious dimension (Khamaisi, 2008).

(b) Socio-economic status and ethnicity are highly associated in metropolitan Tel Aviv as well as its cities. The association between the socio-economic and the ethnic dimension is expressed at the two geographic scales, the city and the metropolitan area. The spatial patterns accompanying these dimensions tend to association on the metropolitan level but primarily on the city level. However, this association does not prevent the formation of sectorconcentric patterns in many cities.

The association between ethnicity and socio-economic status nonetheless evidences asymmetry, with social areas differentiated solely by ethnicity more prevalent than social areas differentiated solely by socio-economic status. The latter areas are generally associated with an identifiable ethnic identity. In any case, the association of a person's socio-economic status (income and education) with her ethnic affiliation represents, even today, a major layer in Israeli society's social structure (Cohen, 1998) that finds visible expression in the residential domain. 
(c) A metropolitan area's cities are distinct socio-spatial entities that maintain a spatial structure of social areas. The low level of association between the family status and the socio-economic and ethnic dimensions creates conditions conducive to the formation of a sector-concentric spatial pattern and the consolidation of diverse social areas in cities within the Tel Aviv metropolitan area. In general, the city level is revealed to be the geographic scale on which the most significant social segregation was found.

We can attribute this phenomenon to the unique history of urban settlement in Israel, which was characterized by waves of immigration especially during the early years of the State's existence. During this period, official public housing policies were implemented within the framework of immigrant absorption and population distribution, policies that aimed at the more or less equal residential distribution of immigrants among the urban settlements of metropolitan Tel Aviv (Efrat, 1988; Gonen, 1966; Kalush and Lu-Yuan 2000). As the immigrants generally represented a weak socio-economic population and of predominantly Mizrahi origin, they were settled in distinctive geographical areas, in isolation from the residence areas populated by a population comprised of veteran, relatively wealthy and Ashkenazi individuals. These polices established the conditions for social segregation and polarization at the city level.

In light of the research findings we can depict the socio-spatial structure of Israeli cities as characterized by significant ethnic residential differentiation and considerable association between ethnic and socio-economic dimensions. The existence of a common socio-spatial structure on the metropolitan and on the city level bears witness to the force of these trends in Israeli society. The conclusion to be reached on the basis of the comparison between these two geographic scales - the city and the metropolitan area - is that the city represents the dominant geographic scale with respect to residential differentiation. However, considering the structural tension between these two geographic scales, a long-term investigation is required that takes the development of metropolitan Tel Aviv into consideration.

\section{References}

BATTY M. (2005), Cities and complexity: understanding cities with cellular automata, agent-based models, and fractals, Mass: MIT Press, Cambridge.

York.

BERRY B.J.L., KASARDA J.D. (1977), Contemporary urban ecology, Macmillan, New New Jersey.

CADWALLADER M. (2001), Urban Geography: An analytical approach, Prentice Hall,

CASTELLS M. (2002), The Castells reader on cities and social theory, Ida Susser (ed.), Malden, Mass.,Blackwell Publishers.

COHEN Y. (1998) Socioeconomic Gaps between Mizrachim and Ashkenazim 19751995, Israeli Sociology, 1 (1), p. 115-134, (in Hebrew).

DAVIES W. K. D. (1984, ) Factorial ecology, Gower Press, Aldershot.

DAVIES W. K. D., MURDIE R.A. (1991), Consistency and differential impact in urban social dimensionality - interurban variations in the 24 metropolitan-areas of Canada, Urban Geography,12(1), p.55-79.

EFRAT E. (1984), Urbanization in Israel, Croom Helm, London.

FARRELL C.R. (2008), Bifurcation, Fragmentation, or Integration? The Racial and Geographic Structure of Metropolitan Segregation, 1990-2000, Urban Studies, 45 (3), p.467499.

FISCHER C.S., STOCKMAYER G., STILES J., HOUT M. (2004), Distinguishing the geographic levels and social dimensions of U.S. metropolitan segregation, 1960-2000, Demography, 41 (1), p.37-59. 
GONEN A. (1995), Between city and suburb, Avebury, Aldershot.

GRADUS Y. (1976), Factorial Ecology in a 'Controlled' Urban System: The Case of Metropolitan Haifa, Israel, Geografiska Annaler 58(B), p.59-66.

GRAUDUS Y., BLUSTEIN-LIVNON R. (2001), The Urban Ecology of Beer-Sheva in the Era of Globalization, in A Socio-Political Atlas, Negev Center for Regional Development, Ben-Gurion University of the Negev (in Hebrew).

HASSON S., CHOSHEN M. (2003), The Socio-Spatial Structure of the Tel Aviv Metropolitan Area, Floersheimer Institute for Policy Studies, Jerusalem (in Hebrew).

HERSHKOVITZ S. (1984), Social Diversity in Tel Aviv: The Spatial Pattern, The Jerusalem Institute for Israel Studies, No 9, Jerusalem.

KALLUS R., LAW-YONE H. (2000), National Home/ Personal Home: The Role of Public Housing in Shaping Space, Theory and Criticism,16, p.157-185 (in Hebrew).

KHAMAISI R. (2008), The Arab Population in Mixed Cities in Israel, Shatil, Jerusalem (in Hebrew).

KRAKOVER S. (1989), Social ecology of Medium size cities: the case of Ashqelon and Rehovot, Merhavim, 3, Tel Aviv, p.103-123 (in Hebrew).

LE BOURDAIS C., BEAUDRY M. (1988), The changing residential structure of Montreal 1971-81, Canadian Geographer, 32, p.98-113.

REARDON S.F. et al. (2008), The geographic scale of metropolitan racial segregation, Demography, 45, p.489-514.

REARDON S.F. et al. (2009), Race and space in the 1990s: Changes in the geographic scale of racial residential segregation, 1990-2000, Social Science Research, 38, p.55-70.

SCHNELL I. (2009), Social areas in Tel Aviv, in B.A. Kipnis (ed.), Tel Aviv-Yafo: From a garden suburb to a world city: The First One Hundred Years, Tel Aviv (in Hebrew).

SHACHAR A. (1977), The planning of urbanized area: a metropolitan approach and the case of the Tel Aviv region, in D. Nachmias and G. Menahem (eds.), Social processes and policy in Tel Aviv Yafo, vol 2, Ramot, Tel Aviv (in Hebrew).

SHACHAR A., HERSHKOVITZ S., STIER M. (1978), Social Areas in Metropolitan TelAviv in the Period 1961-1972, Studies in the Geography of Israel, 10 (1978), p.1-30 (in Hebrew).

WYLY E.K (1999), Continuity and Change in the Restless Urban Landscape, Economic Geography, Vol. 75, No. 4, p.309-338.

YONAH Y., SHENHAV Y. (2005), What is Multiculturalism? On the Politics of Identity in Israel, Bavel,Tel-Aviv (in Hebrew).

Received at : 04.11.2010

Revised at: 10.12 .2010

Accepted for publication at: 15.12.2010 
